\title{
ANALISIS TINGKAT AKURASI PENETAPAN NILAI JUAL OBJEK PAJAK (NJOP) BUMI DENGAN MENGGUNAKAN METODE ASSESSMENT SALES RATIO DI KOTA BANDA ACEH
}

\author{
Nadia Hudja*1 ${ }^{1}$ Wida Fadhlia ${ }^{* 2}$ \\ ${ }^{1,2}$ Program Studi Akuntansi Fakultas Ekonomi dan Bisnis Universitas Syiah Kuala \\ e-mail: dianhudja@gmail.com ${ }^{* 1}$, wida.fadhlia@ unsyiah.ac.id $^{* 2}$
}

\begin{abstract}
This study aims to determine the suitability of the Assesment Ratio (AR) in each subdistrict of Banda Aceh based on the regulations set by Directorat General of Taxes and to find out the existence of intervals for Tax Object Sales Value (NJOP) assignment in Banda Aceh based on the standards set by the International Association of Assessing Officers (IAAO). The method used in this study is descriptive quantitative by testing ASR for ratio studies, measurement of central tendency, and measurement of variability. The results of this study showed that during the 3 research assessment ratios (AR) in each sub-district in the city of Banda Aceh, which consisted of 9 sub-districts all were below the standard recommended by the Director General of Taxes and the IAAO or under-assessment so that a reassessment was needed.
\end{abstract}

Keywords: Akurasi, PBB-P2, NJOP, Assessment Ratio

\section{Pendahuluan}

Tanah (bumi) merupakan salah satu golongan aset berwujud (tangible asset) yang sangat peka terhadap kondisi yang terjadi dalam masyarakat sehingga nilai tanah cenderung berubah mengikuti perkembangan yang ada. Nilai tanah dipengaruhi oleh kepadatan penduduk, jarak ke pusat kota, lebar jalan, kondisi jalan, ketersediaan fasilitas umum, dan yang terakhir yaitu faktor lingkungan yang bebas dari banjir (Bintang et al., 2017; Pramana, 2017; Marpaung, 2011; Sutawijaya, 2004; F., Basong, \& Tagala, 2003). Atas pemanfaatan yang digunakan oleh masyarakat dikenakan Pajak Bumi dan Bangunan (PBB) dari kepemilikan tanah tersebut. Pajak yang telah dibayarkan akan digunakan untuk membiayai pengeluaran pemerintah untuk kemakmuran rakyat \{pasal 1(1) UU No. 28 Tahun 2007\}.

PBB dibagi menjadi dua, yaitu PBB-P2 (Pajak Bumi dan Bangunan Perdesaan dan Perkotaan) yang di kelola pemerintah daerah kabupaten/kota berdasarkan UU No. 28 tahun 2009 Tentang Pajak Daerah dan Retribusi Daerah dan PBB Perkebunan, Perhutanan, dan Pertambangan yang masih dikelola oleh pemerintah pusat (pajak.go.id, 14 April 2012). Dengan demikian, PBB-P2 merupakan salah satu sumber penerimaan daerah yang dikategorikan dalam Pendapatan Asli Daerah (PAD) Kabupaten atau Kota.
Penerimaan daerah dari PBB-P2 ditentukan oleh NJOP (Nilai Jual Objek Pajak). NJOP merupakan dasar pengenaan $\mathrm{PBB}$ yang ditetapkan oleh Kepala Daerah selama tiga tahun sekali (UU No. 28 Tahun 2009; Qanun Kota Banda Aceh Nomor 12 Tahun 2011), sehingga semakin tinggi NJOP maka semakin tinggi penerimaan daerah. NJOP diperoleh dari harga rata-rata yang didapatkan dari transaksi jual beli secara wajar (UU No. 12 Tahun 1985; UU No. 28 Tahun 2009; Qanun Kota Banda Aceh Nomor 12 Tahun 2011). NJOP merupakan cerminan dari harga pasar atau harga yang terjadi saat jual beli. Hal ini bertujuan agar daerah memperoleh penerimaan secara optimal. Pada praktiknya, NJOP tidak selalu sama dengan nilai pasar, NJOP dapat lebih tinggi ataupun lebih rendah dari nilai pasar (Mursito \& Samrotun, 2014).

Tribunnews.com memberitakan bahwa harga yang berlaku di pasar sangat jauh berbeda dengan harga yang ditetapkan dalam NJOP, sehingga terjadi ketimpangan harga. Adapun contoh kasusnya yaitu terjadi di Jl. Mr Moh Hasan Banda Aceh, NJOP yang ditetapkan yaitu sebesar Rp 1.032.000,00 per meter. Pada kenyataannya harga tanah di daerah tersebut mencapai harga Rp 2.000.000,00 hingga Rp 3.000.000,00 per meter (tribunnews.com, 4 September 2014). Petumbuhan harga tanah di Kota Banda Aceh meningkat pesat setelah terjadinya bencana tsunami 
2004, sehingga harga rumah ikut meningkat (aceh.tribunnews.com, 28 April 2013). Selanjutnya, menurut pernyatan Pengelola Data Ektensifikasi dan Intensifikasi PBB UPTB PBB dan BPHTB ada penjualan yang terjadi pada tahun 2018 di Gp. Keuramat dengan NJOP Rp 702.000,00/ $\mathrm{m}^{2}$ sedangkan harga pasarnya $\mathrm{Rp} 1.330 .000,00 / \mathrm{m}^{2}$. Ketimpangan harga yang terjadi di lapangan yang akan digunakan sebagai pedoman atau acuan untuk penetapan NJOP tanah menunjukkan ketidakakuratan.

Ketidakakuratan penetapan NJOP dapat dievaluasi dengan menggunakan metode Assessment Sales Ratio (Surat Edaran Direktur Jenderal Pajak Nomor SE - 01/PJ.6/2003). Adapun rasio yang sering digunakan untuk kepentingan perpajakan yaitu Assessment Ratio (AR) (Elriza, 2014). Penggunaan metode ini dapat menjadi acuan untuk menentukan penerapan NJOP yang ditetapkan lebih tinggi (overassessment) atau lebih rendah (under-assessment) dari nilai pasar, sehingga dapat diketahui bagaimana NJOP yang diterapkan di masyarakat. Penentuan ini berdasarkan pada Surat Edaran Direktur Jenderal Pajak Nomor SE - 09/PJ.6/2003 yaitu minimal 80\%. Selain itu, pedoman lain yang digunakan dalam penentuan lebih tinggi (over-assessment) atau lebih rendah (under-assessment) adalah interval yang dikeluarkan oleh IAAO (International Association of Assessing Officer).

\section{Tinjauan Pustaka}

\section{Pajak Bumi dan Bangunan}

PBB adalah suatu pajak yang dikenakan atas tanah dan bangunan disebabkan adanya pemanfaatan dan/atau yang mempunyai pengaruh terhadap kedudukan sosial dan ekonomi bagi yang memanfaatkannya (UU No. 12 Tahun 1985). PBB merupakan salah satu sumber penerimaan Negara yang dipungut atas kekayaan berbentuk tanah dan bangunan (Lubis et al., 2010:114).

\section{Pajak Bumi dan Bangunan Perdesaan dan Perkotaan (PBB-P2)}

PBB-P2 merupakan objek pajak yang meliputi kawasan yang digunakan untuk pertanian, perkantoran, pertokoan, perumahan, industri dan objek khusus perkotaan (Rusjdi, 2008:24). Pemerintah daerah yang mengelola PBB-P2 dengan baik akan mudah dalam menetapkan target penerimaan dari sektor PBB-P2 (Kumoro \& Ariesanti, 2017).

\section{Nilai Jual Objek Pajak (NJOP)}

NJOP (Nilai Jual Objek Pajak) adalah dasar pengenaan PBB-P2 (Auliani, Kamio, \& Supadi, 2012). NJOP merupakan hasil dari penilaian yang digunakan sebagai acuan dalam pengenaan pajak (Aprianing, Wilopo, \& Mayowan, 2016) yang diperoleh dari harga rata-rata yang didapatkan dari transaksi jual beli secara wajar (UU No. 12 Tahun 1985; UU No. 28 Tahun 2009; Qanun No. 12 Tahun 2011).

\section{Assessment Sales Ratio (ASR)}

ASR merupakan sebuah metode yang digunakan untuk mengevaluasi masalah yang berkaitan dengan PBB yaitu dalam hal penetapan, keseragaman, keadilan, mengindentifikasi permasalahan mengenai analisis pasar, hingga menyelesaikan keberatan tentang prosedur penilaian dan lain sebagainya (Wakas, Karamoy, \& Runtu, 2015).

Kegunaan studi Assessment Sales Ratio yaitu: 1) pemeliharaan assessment atau penilaian asset agar selalu berada pada tingkat yang dapat diterima (uniformity) yang dilakukan dengan pengukuran tendensi sentral. Hal ini bertujuan untuk mengevaluasi assessment performance agar mengetahui daerah yang mempunyai AR terlalu tinggi, sehingga dapat segera di perbaiki. 2) untuk menentukan wilayah yang perlu dilakukan penilaian kembali (re-appraisal). Penentuan ini menggunakan analisis variabilitas. 3) adil dalam menetapkan PBB yang dianalisis melalui regresivitas atau progresivitas. Bertujuan agar penetapan PBB bersifat adil terhadap properti bernilai rendah atau properti bernilai tinggi (Sugiato 2006:26 dalam Suryawati et al., 2010). Berdasarkan Surat edaran Direktur Jenderal Pajak Nomor SE-09/PJ.6/2003, ASR minimal yaitu $80 \%$.

Setelah mendapatkan hasil AR, maka selanjutnya melakukan perhitungan untuk menentukan tingkat uniformity, keperluan penilaian ulang (reappraisal) serta keadilan dengan menggunakan rumus dan standar yang dikeluarkan oleh IAAO (International Association of Assessing Officer). IAAO merekomendasikan AR berada pada interval 90\%-110\%. Adapun standar akurasi penetapan menurut IAAO yaitu: 
a. Jika mean/median > 1,10 (110\%) berarti overassessment.

b. Jika mean/median $<0,90(90 \%)$ berarti underassessment.

c. Jika mean/w-mean $>1,10(110 \%)$ berarti terjadi regresivitas.

d. Jika mean/w-mean $<0,90(90 \%)$ berarti terjadi progresivitas.

\section{Metode Penelitian}

Sampel dan Data

Sampel dalam penelitian ini adalah transaksi jual beli tanah kosong yang terjadi selama 3 tahun (2016-2018) di seluruh kecamatan di Kota Banda Aceh, yang mana dalam transaksi tersebut telah diketahui nilai NJOP dan harga jual dari objek pajak PBB. Adapun jumlah kecamatan yang berada di Kota Banda Aceh yaitu 9 Kecamatan (organisasi.org). Pengambilan sampel dalam penelitian ini menggunakan probability sampling dengan teknik stratified random sampling (pengambilan sampel berstrata).

Penarikan sampel dalam penelitian ini menggunakan tabulasi Cohen, Manion \& Marrison (2007), yaitu apabila populasi sebesar 4.756 maka peneliti dapat membulatkannya ke populasi terdekat yaitu 5.000. Taraf keyakinan (confidance level) penelitian sebesar $90 \%$ dan interval keyakinan sebesar 0,1. Maka diperoleh jumlah sampel sebesar 258 transaksi.

Penelitian ini menggunakan sumber data sekunder. Data diperoleh dari publikasi pemerintah yaitu Keputusan Wali Kota Banda Aceh Nomor 242 Tahun 2017 Tentang Klasifikasi dan Penetapan Nilai Jual Objek Pajak Kota Banda Aceh serta Nilai Pasar hasil dari traksaksi jual beli tanah kosong dalam jangka waktu 3 tahun (2016-2018).

Pengumpulan data dilakukan melalui teknik dokumentasi, yaitu dengan cara mengumpulkan data secara langsung yang bersumber dari BPKK dan studi pustaka dengan memperoleh informasi dari artikel, Undang-Undang, Peraturan Perintah, buku dan sumber lainnya yang berhubungan dengan masalah yang di teliti.

\section{Pengukuran Variabel \\ Nilai Jual Objek Pajak (NJOP)}

NJOP merupakan dasar pengenaan pajak yang diperoleh dari harga rata-rata transaksi jual beli yang terjadi secara wajar (UU No. 12 Tahun 1985; UU No. 28 Tahun 2009; Qanun No.12 Tahun 2011). Berdasarkan Surat Edaran Direktur Jenderal Pajak Nomor SE-01/PJ.6/2003 penetapan NJOP dapat dievaluasi menggunakan metode ASR. ASR di ukur melalui studi rasio, pengukuran tendensi sentral dan pengukuran variabilitas (Sugiato 2006:26 dalam Suryawati et al., 2010).

\section{Metode Analisis Data}

Metode analisis data yang digunakan dalam penelitian ini yaitu metode ASR, yang terdiri dari studi rasio, pengukuran tendensi sentral, dan pengukuran variabilitas. Data diolah dengan menggunakan program Microsoft Excel 2013.

\section{Hasil Dan Pembahasan \\ Deskripsi Data}

Populasi dalam penelitian ini yaitu 4.756 kasus jual beli tanah kosong yang terjadi selama 3 tahun di 9 kecamatan. Adapun sampel yang digunakan yaitu 258 kasus dengan merujuk pada tabel cohen et al., (2007), dengan rincian tahun 2016 sebanyak 94 kasus, 2017 sebanyak 84 kasus dan 2018 sebanyak 80 kasus. Data dalam penelitian ini murni bersumber dari BPKK Banda Aceh. Semua data transaksi yang terpilih menjadi sampel merupakan wewenang dari pihak BPKK Banda Aceh.

\section{Studi Rasio}

Studi rasio bertujuan untuk mengetahui besaran rasio antara NJOP terhadap nilai pasar, dengan rasio minimal yaitu $80 \%$ sesuai dengan ketetapan Dirjen Pajak. Adapun rasio yang digunakan dalam perpajakan adalah AR (Assessment Ratio) (Elriza, 2014). Secara matematis studi rasio dapat dihitung dengan menggunakan formula sebagai berikut:

$$
\mathrm{AR}=\frac{A_{i}}{S_{i}}
$$

Keterangan:

$$
\begin{aligned}
\mathrm{AR} & =\text { Assessment Sales Ratio } \\
\mathrm{Ai} & =\text { Nilai yang ditetapkan (assessment value) } \\
& \text { (NJOP) } \\
\mathrm{Si} & =\text { Nilai pasar (market value) }
\end{aligned}
$$


Dari studi rasio diperoleh hasil sebagai berikut:

Tabel 4.1

Assessment Ratio per Kecamatan Tahun 2016

\begin{tabular}{|l|c|c|c|}
\hline \multicolumn{1}{|c|}{ Kecamatan } & AR & AR\% & Keterangan \\
\hline Baiturrahman & 0,534 & $53,4 \%$ & Under-assessment \\
\hline Banda Raya & 0,495 & $49,5 \%$ & Under-assessment \\
\hline Jaya Baru & 0,471 & $47,1 \%$ & Under-assessment \\
\hline Kuta Alam & 0,504 & $50,4 \%$ & Under-assessment \\
\hline Kuta Raja & 0,541 & $54,1 \%$ & Under-assessment \\
\hline Lueng Bata & 0,526 & $52,6 \%$ & Under-assessment \\
\hline Meuraksa & 0,494 & $49,4 \%$ & Under-assessment \\
\hline Syiah Kuala & 0,469 & $46,9 \%$ & Under-assessment \\
\hline Ulee Kareng & 0,485 & $48,5 \%$ & Under-assessment \\
\hline
\end{tabular}

Sumber: Data diolah (2019)

Pada pengujian AR tahun 2016, level of assessment dari semua kecamatan berada pada level under-assessment. Hal ini menunjukkan penetapan NJOP berada di bawah harga pasar. Pada Tabel 4.1 dapat dilihat bahwa hasil yang diperoleh berada jauh dari yang direkomendasikan oleh Dirjen Pajak sebesar $80 \%$. Adapun hasilnya yaitu berada antara $46,9 \%$ $54,1 \%$, dimana kecamatan paling rendah adalah Syiah Kuala dan tertinggi adalah Kuta Raja. Selisih antara angka yang direkomendasikan dengan angka yang dihasilkan yaitu dengan rata-rata $29,8 \%$. Selisih ini dapat terjadi karena Pemkot Banda Aceh masih mengadopsi NJOP yang dikeluarkan oleh KPP Pratama Banda Aceh. Hal ini harusnya dapat menjadi pendapatan bagi pemkot Banda Aceh dalam memaksimalkan PAD melalui pemungutan PBB-P2.

Tabel 4.2

Assessment Ratio per Kecamatan Tahun 2017

\begin{tabular}{|l|c|c|c|}
\hline Kecamatan & AR & AR\% & Keterangan \\
\hline Baiturrahman & 0,515 & $51,5 \%$ & Under-assessment \\
\hline Banda Raya & 0,483 & $48,3 \%$ & Under-assessment \\
\hline Jaya Baru & 0,466 & $46,6 \%$ & Under-assessment \\
\hline Kuta Alam & 0,500 & $50,0 \%$ & Under-assessment \\
\hline Kuta Raja & 0,490 & $49,0 \%$ & Under-assessment \\
\hline Lueng Bata & 0,507 & $50,7 \%$ & Under-assessment \\
\hline Meuraksa & 0,470 & $47,0 \%$ & Under-assessment \\
\hline Syiah Kuala & 0,485 & $48,5 \%$ & Under-assessment \\
\hline Ulee Kareng & 0,462 & $46,2 \%$ & Under-assessment \\
\hline
\end{tabular}

Sumber: Data diolah (2019)
Pada tahun 2017 semua kecamatan juga berada pada level under-assessment. Pada tahun ini selisih antara persetase yang direkomendasikan dengan hasil yang diperoleh lebih tinggi dari tahun sebelumnya. Kecamatan yang memperoleh AR terendah adalah Ulee Kareng dengan persentase 46,2\% dan tertinggi yaitu Baiturrahman dengan persentase 51,5\%. Adapun selisih rata-rata yaitu $31,4 \%$ atau naik sebesar $1,6 \%$. Padahal pada tahun 2017 pemkot Banda Aceh baru saja memperbaharui penetapan NJOP, tetapi AR yang diperoleh semakin menurun. Hal ini mengindikasikan bahwa kinerja penilai kurang baik dalam menetapkan nilai NJOP, karena setelah pembaharuan AR yang diperoleh harusnya meningkat mendekati $80 \%$. Disisi lain, AR yang dihasilkan juga dipengaruhi oleh pemilihan sampel yang digunakan, walaupun semuanya berada di bawah standar yang direkomendasikan hanya saja tingkat selisih yang dihasilkan berbeda antara satu dengan lainnya. Adapun potensi pajak PBB-P2 yang masih dapat diterima oleh pemkot Banda Aceh yaitu sebesar 31,4\%.

\section{Tabel 4.3}

Assessment Ratio per Kecamatan Tahun 2018

\begin{tabular}{|l|c|c|c|}
\hline \multicolumn{1}{|c|}{ Kecamatan } & AR & AR\% & Keterangan \\
\hline Baiturrahman & 0,659 & $65,9 \%$ & Under-assessment \\
\hline Banda Raya & 0,353 & $35,3 \%$ & Under-assessment \\
\hline Jaya Baru & 0,371 & $37,1 \%$ & Under-assessment \\
\hline Kuta Alam & 0,460 & $46,0 \%$ & Under-assessment \\
\hline Kuta Raja & 0,467 & $46,7 \%$ & Under-assessment \\
\hline Lueng Bata & 0,505 & $50,5 \%$ & Under-assessment \\
\hline Meuraksa & 0,378 & $37,8 \%$ & Under-assessment \\
\hline Syiah Kuala & 0,380 & $38,0 \%$ & Under-assessment \\
\hline Ulee Kareng & 0,442 & $44,2 \%$ & Under-assessment \\
\hline
\end{tabular}

Sumber: Data diolah (2019)

Pada tahun 2018 selisih rata-rata yang menjadi potensi penerimaan pajak yaitu $35,4 \%$ atau naik sebesar 4\%. Pada tahun ini semua kecamatan mengalami penurunan AR kecuali Baiturrahman, hal ini karena dipengaruhi oleh pengambilan kasus yang dijadikan sampel. Kecamatan yang memperoleh AR tertinggi adalah Baiturrahman yaitu $64,9 \%$ dengan selisih terendah terhadap rekomendasi yaitu $14,1 \%$. Kemudian kecamatan yang memperoleh terendah adalah Jaya Baru yaitu 37,1\% dengan selisih tertinggi terhadap rekomendasi yaitu sebesar $42,9 \%$. AR di 
kecamatan Jaya Baru lebih rendah dari AR yang direkomendasikan mendekati 50\%. Selama 3 tahun pengamatan AR yang dihasilkan seluruhnya berada di bawah standar yang direkomendasikan yaitu kurang dari $80 \%$. Hal ini menandakan bahwa Pemkot Banda Aceh telah menyia-nyiakan potensi yang ada. Padahal tujuan dari peralihan PPB-P2 menjadi hak daerah adalah agar daerah dapat memaksimalkan potensi yang ada.

\section{Pengukuran Tendensi Sentral}

Pengukuran tendensi sentral yaitu pengukuran yang dikeluarkan oleh IAAO (2017) dengan berpedoman pada IAAO (2013) yang terdiri dari mean, median, dan weighted mean yang kemudian dikembangkan dengan penambahan mean/median dan mean/weighted mean, dengan interval 90\%-110\%.

Tabel 4.4

Hasil Pengukuran Tendensi Sentral Tahun 2016

\begin{tabular}{|l|l|l|}
\hline \multicolumn{1}{|c|}{$\begin{array}{c}\text { Tendensi } \\
\text { Sentral }\end{array}$} & Nilai & \multicolumn{1}{|c|}{ Keterangan } \\
\hline AR Mean & 0,496 & $\begin{array}{l}\text { Penilaian NJOP } \\
\text { dibandingkan dengan nilai } \\
\text { pasar sebesar 49,6\%. }\end{array}$ \\
\hline Median & 0,512 & $\begin{array}{l}\text { Nilai tengah yang } \\
\text { dihasilkan dari penetapan } \\
\text { NJOP terhadap nilai pasar } \\
\text { yaitu 0,512. }\end{array}$ \\
\hline Weighted mean & 0,513 & $\begin{array}{l}\text { Bobot dari nilai rata-rata } \\
\text { NJOP terhadap nilai pasar } \\
\text { yaitu sebesar 0,513. }\end{array}$ \\
\hline Mean/Median & 0,968 & $\begin{array}{l}\text { Tidak terjadi } \text { under- } \\
\text { assessment } \text { ataupun } \text { over- } \\
\text { assessment }\end{array}$ \\
\hline $\begin{array}{l}\text { Mean/Weighted } \\
\text { Mean }\end{array}$ & 0,966 & $\begin{array}{l}\text { Hasil yang diperoleh } \\
\text { proporsional dalam } \\
\text { penetapan NJOP. }\end{array}$ \\
\hline
\end{tabular}

Sumber: Data diolah (2019)

1. Mean (rata-rata hitung)

Mean merupakan rata-rata dari nilai AR yang dibagi dengan jumlah sampel penelitian.

$$
\text { ARmean }=\frac{47,073}{94}=0,496
$$

2. Median (nilai tengah)

Median merupakan nilai tengah dari rasio-rasio apabila diurutkan dari nilai terendah hingga nilai tertinggi, sehingga diperoleh median sebesar 0,512 .

\section{Weighted mean}

$$
\begin{aligned}
\text { weighted mean } & =\frac{\sum \text { NJOP }}{\sum \text { Nilai Pasar }} \\
& =\frac{15.660 .000}{30.526 .000}=0,513
\end{aligned}
$$

\section{Mean/Median}

$$
\frac{\text { Mean }}{\text { Median }}=\frac{0,496}{0,512}=0,968
$$

\section{Mean/Weighted Mean}

$$
\frac{\text { Mean }}{\text { Weighted Mean }}=\frac{0,496}{0,513}=0,966
$$

Pada tahun 2016 mean yang dihasilkan sebesar 0,496 atau $49,6 \%$, angka tersebut tidak memenuhi standar IAAO atau berada pada level underassessment. Hal ini menunjukkan bahwa NJOP jauh berada di bawah harga pasar. Median yang dihasilkan yaitu 0,512. Lalu nilai dari weighted mean yaitu 0,513. Hasil tersebut belum memeuhi kriteria yang dikeluarkan oleh IAAO. Data yang menjadi sampel dalam penelitian ini cenderung sama atau berimbang antara yang berada di bawah nilai rata-rata dengan diatas nilai rata-rata. Hal inilah yang menyebabkan hasil dari pengukuran mean/median sebesar 0,968. Hasil tersebut dapat dikatakan berimbang karena telah berada dalam interval yang direkomendasikan. Selanjutnya analisis mean/weighted mean yang hasilnya proporsional yaitu 0,966 atau sesuai standar IAAO.

Tabel 4.5

Hasil Pengukuran Tendensi Sentral Tahun 2017

\begin{tabular}{|c|c|c|}
\hline $\begin{array}{c}\text { Tendensi } \\
\text { Sentral }\end{array}$ & Nilai & \multicolumn{1}{|c|}{ Keterangan } \\
\hline AR Mean & 0,481 & $\begin{array}{l}\text { Penilaian NJOP } \\
\text { dibandingkan dengan nilai }\end{array}$ \\
\hline
\end{tabular}




\begin{tabular}{|l|l|l|}
\hline \multicolumn{1}{|c|}{$\begin{array}{c}\text { Tendensi } \\
\text { Sentral }\end{array}$} & Nilai & \multicolumn{1}{|c|}{ Keterangan } \\
\hline Median & 0,483 & $\begin{array}{l}\text { Nilai tengah yang } \\
\text { dihasilkan dari penetapan } \\
\text { NJOP terhadap nilai pasar } \\
\text { yaitu 0,483. }\end{array}$ \\
\hline Weighted mean & 0,494 & $\begin{array}{l}\text { Bobot dari nilai rata-rata } \\
\text { NJOP terhadap nilai pasar } \\
\text { yaitu sebesar 0,494. }\end{array}$ \\
\hline Mean/Median & 0,995 & $\begin{array}{l}\text { Tidak terjadi } \text { under- } \\
\text { assessment ataupun } \text { over- } \\
\text { assessment }\end{array}$ \\
\hline $\begin{array}{l}\text { Mean/Weighted } \\
\text { Mean }\end{array}$ & 0,972 & $\begin{array}{l}\text { Hasil yang diperoleh } \\
\text { proporsional dalam } \\
\text { penetapan NJOP. }\end{array}$ \\
\hline
\end{tabular}

Sumber: Data diolah (2019)

\section{Mean (rata-rata hitung)}

Mean merupakan rata-rata dari nilai AR yang dibagi dengan jumlah sampel penelitian.

$$
\text { ARmean }=\frac{40,367}{84}=0,481
$$

2. Median (nilai tengah)

Median merupakan nilai tengah dari rasiorasio apabila diurutkan dari nilai terendah hingga nilai tertinggi, sehingga diperoleh median sebesar 0,483 .

\section{Weighted mean}

$$
\begin{aligned}
\text { weighted mean } & =\frac{\sum \text { NJOP }}{\sum \text { Nilai Pasar }} \\
& =\frac{15.356 .000}{31.074 .000}=0.494
\end{aligned}
$$

\section{Mean/Median}

$$
\frac{\text { Mean }}{\text { Median }}=\frac{0,481}{0,483}=0,995
$$

\section{Mean/Weighted Mean}

$$
\frac{\text { Mean }}{\text { Weighted Mean }}=\frac{0,481}{0,494}=0,972
$$

Pada tahun 2017 mean yang dihasilkan berada jauh dibawah standar yaitu 0,481 atau $48,1 \%$. Setelah data diurutkan, median yang diperoleh sebesar 0,483 dan weighted mean sebesar 0,494. Hasil yang diperoleh belum memenuhi standar IAAO atau underassessment. Sama seperti tahun 2016, data yang menjadi sampel cenderung sama antara data di atas median dengan data yang berada dibawah median, hal ini menyebabkan hasil dari mean/median dan mean/weighted mean telah memenuhi standar yaitu 0,995 dan 0,972. Walaupun hasil dari mean, median, dan weighted mean berada di bawah standar.

Tabel 4.6

Hasil Pengukuran Tendensi Sentral Tahun 2018

\begin{tabular}{|l|c|l|}
\hline \multicolumn{1}{|c|}{$\begin{array}{c}\text { Tendensi } \\
\text { Sentral }\end{array}$} & Nilai & \multicolumn{1}{|c|}{ Keterangan } \\
\hline AR Mean & 0,408 & $\begin{array}{l}\text { Penilaian NJOP } \\
\text { dibandingkan dengan nilai } \\
\text { pasar sebesar 40,8\%. }\end{array}$ \\
\hline Median & 0,400 & $\begin{array}{l}\text { Nilai tengah yang } \\
\text { dihasilkan dari penetapan } \\
\text { NJOP terhadap nilai pasar } \\
\text { yaitu 0,400. }\end{array}$ \\
\hline Weighted mean & 0,434 & $\begin{array}{l}\text { Bobot dari nilai rata-rata } \\
\text { NJOP terhadap nilai pasar } \\
\text { yaitu sebesar 0,434. }\end{array}$ \\
\hline Mean/Median & 1,019 & $\begin{array}{l}\text { Tidak terjadi under- } \\
\text { assessment ataupun over- } \\
\text { assessment }\end{array}$ \\
\hline $\begin{array}{l}\text { Mean/Weighted } \\
\text { Mean }\end{array}$ & 0,938 & $\begin{array}{l}\text { Hasil yang diperoleh } \\
\text { proporsional dalam } \\
\text { penetapan NJOP. }\end{array}$ \\
\hline
\end{tabular}

Sumber: Data diolah (2019)

1. Mean (rata-rata hitung)

Mean merupakan rata-rata dari nilai AR yang dibagi dengan jumlah sampel penelitian.

$$
\text { ARmean }=\frac{32.603}{80}=0,408
$$

2. Median (nilai tengah)

Median merupakan nilai tengah dari rasiorasio apabila diurutkan dari nilai terendah hingga nilai tertinggi, sehingga diperoleh median sebesar 0,400 . 
3. Weighted mean

$$
\begin{aligned}
\text { weighted mean } & =\frac{\sum \text { NJOP }}{\sum \text { Nilai Pasar }} \\
& =\frac{11.190 .000}{25.754 .000}=0.434
\end{aligned}
$$

\section{Mean/Median}

$$
\frac{\text { Mean }}{\text { Median }}=\frac{0,408}{0,400}=1,019
$$

\section{Mean/Weighted Mean}

$$
\frac{\text { Mean }}{\text { Weighted Mean }}=\frac{0,408}{0,434}=0,938
$$

Pada tahun 2018, mean yang dihasilkan sebesar 0,408 atau $40,8 \%$, lebih rendah dari tahun-tahun sebelumnya dan tentunya berada di bawah standar yang direkomendasikan. Median yang dihasilkan sebesar 0,400 dan weighted mean bernilai 0,434. Ketiga pengukuran tersebut masih berada dalam kategori under-assessment. Sedangkan mean/median dan mean/weighted mean berada dalam kategori proporsioal atau tidak terjadi under-assessment atau over-assessment maupun progresivitas atau regresivitas yaitu 1,019 dan 0,938. Adapun penyebabnya sama seperti tahun-tahun sebelumnya yaitu data atas dan bawah median cenderung sama, sehingga ketika terjadi pembagian akan memperoleh hasil sesuai standar.

Pada analisis pengukuran tendensi sentral mean, median dan weighted mean seluruhnya selama 3 tahun berada di bawah interval yang dikeluarkan oleh IAAO. Hal ini berbeda dengan mean/weighted mean dan median/weighted mean yang menunjukkan hasil yang proporsional. Ketidakselarasan ini terjadi karena sampel yang digunakan cenderung sama, sehingga hasil dari mean, median dan weighted mean tidak jauh berbeda. Ketika terjadi pembagian maka secara matematis hasilnya akan mendekati 1 atau sesuai interval yaitu 0,90-1,10.

Hal ini selaras dengan hasil penelitian yang dilakukan oleh Elriza (2014) dimana pada Kecamatan Sario Kota Manado terjadi under-assessment atau NJOP berada di bawah nilai pasar. Selanjutnya hasil penelitian ini juga didukung dengan penelitian yang dilakukan oleh Wakas et al., (2015) di Kecamatan Manpanget, dimana AR berada di bawah interval yang ditetapkan oleh IAAO. Monding \& Pusung (2016) melakukan penelitian di Kecamatan Paal Dua dan hasilnya menunjukkan bahwasaya NJOP diwilayah tersebut berada di bawah standar yang direkomendasikan oleh IAAO.

\section{Pengukuran Variabilitas}

Pengukuran variabilitas merupakan pengukuran yang bertujuan untuk mengetahui tingkat keseragaman dan variabilitas penetapan NJOP di setiap kecamatan yang berada di wilayah Kota Banda Aceh. IAAO (2013) menetapkan pengukuran variabilitas terdiri dari COD (Coefficient of Dispersion) dan COV (Coefficient of Variability). COD merupakan sebuah standar yang digunakan untuk menjadi acuan perlu tidaknya dilakukan penilaian ulang. COV merupakan ukuran keseragaman atau data terdistribusi secara normal. Interval COD dan COV dapat dikatakan baik apabila hasil yang diperoleh yaitu sebesar 5\% sampai dengan 20\% untuk kategori tanah kosong yang berada di wilayah perkotaan (IAAO, 2013). Adapun rumus untuk mengitung COD ada sebagai berikut:

Keterangan:

$$
\mathrm{COD}=\frac{100 \times \sum\left|\frac{A i}{S i}-\frac{A}{S m d}\right|}{\frac{A}{S m d} x(n-1)}
$$

$\begin{array}{ll}\mathrm{A} / \mathrm{Smd} & =\text { Median dari rasio } \\ \mathrm{Ai} / \mathrm{Si} & =\text { Assessment ratio }\end{array}$

Selanjutnya rumus untuk mengitung COV adalah sebagai berikut:

$$
\mathrm{COV}=\frac{100 x \sqrt{\sum\left(\frac{A i}{S i}-\frac{A}{S m n}\right)^{2}}}{\frac{A}{S m n} x(n-1)}
$$

Keterangan:

$\begin{array}{ll}\mathrm{A} / \mathrm{Smn} & =\text { Mean dari rasio } \\ \mathrm{Ai} / \mathrm{Si} & =\text { Assessment ratio }\end{array}$

Tabel 4.7

Hasil Pengukuran Variabilitas Tahun 2016

\begin{tabular}{|l|c|}
\hline Pegukuran Variabilitas & Nilai \\
\hline COD $(\%)$ & $6,680 \%$ \\
\hline COV $(\%)$ & $1,526 \%$ \\
\hline
\end{tabular}

Sumber: Data diolah (2019) 
Pengukuran variabilitas pada tahun 2016 mengalami ketidakseragaman. Menurut kategori COD yang dihasilkan tergolong baik yaitu sebesar 6,680\% sedangkan COV berada dibawah standar yaitu $1,526 \%$. Hal ini dikarenakan standar yang dikeluarkan IAAO (2013) untuk tanah kosong yaitu berada pada interval 5\% -20\%. Ketidakseragaman ini terjadi karena nilai COD dan COV berbeda satu dengan lainnya atau salah satu diantara keduanya tidak sesuai standar (Wakas et al., 2015). Ketidakseragaman menunjukkan bahwa kinerja yang kurang baik dalam melakukan NJOP. Selain itu, belum dilakukannya pembaharuan NJOP atau penilaian kembali juga menjadi penyebab timbulnya ketidakseragaman.

\section{Tabel 4.8}

\section{Hasil Pengukuran Variabilitas Tahun 2017}

\begin{tabular}{|l|c|}
\hline Pegukuran Variabilitas & Nilai \\
\hline COD (\%) & $5,875 \%$ \\
\hline COV (\%) & $1,382 \%$ \\
\hline
\end{tabular}

Sumber: Data diolah (2019)

Pada tahun 2017 penetapan NJOP di Kota Banda Aceh mengalami ketidakseragaman. Berdasarkan kategori COD yang dihasilkan tergolong baik yaitu sebesar $5,875 \%$ sedangkan COV masih berada dibawah standar yaitu $1,382 \%$. Hal ini sesuai dengan standar yang dikeluarkan oleh IAAO (2013) untuk tanah kosong yaitu berada pada interval 5\% $20 \%$. Ketidakseragaman ini terjadi karena nilai COD dan COV berbeda satu dengan lainnya atau salah satu diantara keduanya tidak sesuai standar (Wakas et al., 2015). Padahal pada tahun 2017 telah dilakukannya pembaharuan NJOP, yang harusnya ketidakseragaman yang terjadi pada tahun sebelumnya dapat diatasi. Akan tetapi berdasarkan data yang diperoleh peneliti, COD dan COV lebih rendah dari sebelumnya. Dengan demikian, walaupun baru dilakukan pembaharuan NJOP, Pemkot masih harus melihat kembali tentang penetapan NJOP agar perubahan nilai tanah dapat terpantau secara keseluruhan.

Tabel 4.9

Hasil Pengukuran Variabilitas Tahun 2018

\begin{tabular}{|l|c|}
\hline Pegukuran Variabilitas & Nilai \\
\hline COD $(\%)$ & $8,196 \%$ \\
\hline COV $(\%)$ & $2,495 \%$ \\
\hline
\end{tabular}

Sumber: Data diolah (2019)
Pada tahun 2018 COV tidak memenuhi standar yaitu $2,495 \%$ sedangkan COD berada dalam kategori baik yaitu $8,196 \%$. Hal ini sesuai dengan standar yang dikeluarkan oleh IAAO (2013) dimana interval untuk tanah kosong berada antara 5\% hingga $20 \%$. Ketidakseragaman ini mencerminkan bahwa kinerja kurang baik dalam proses penetapan NJOP sehingga diperlukannya penilaian ulang agar nilai tanah dapat terdata secara menyeluruh guna memaksimalkan potensi yang ada untuk meningkatkan penerimaan daerah melaluli PBB-P2. Selain itu, pembaharuan NJOP harusnya dilakukan 3 tahun sekali. Oleh kerena itu, pemkot Banda Aceh melalui Badan Pengelolaan Keuangan Kota harus mengevaluasi penetapan NJOP tahun 2020 dikarenakan pembaharuan terakhir dilakukan pada tahun 2017.

Analisis pengukuran variabilitas selama 3 tahun menunjukkan bahwa seluruhnya nilai COD berada dalam kategori baik atau berada diantara 5\%-20\%. Hal ini terbalik dengan nilai dari COV yang berada di bawah interval yang direkomendasikan oleh IAAO atau di bawah 5\%. Ketidakseragaman antara hasil dari COD dan COV mengindikasikan perlunya dilakukakan penilaian ulang. Hal ini selaras dengan penelitian yang dilakukan oleh Patara \& Tinangon (2016) di Kabupaten Minahasa, dimana pemerintah Kabupaten Minahasa harus melakukan re-appraisal atau penilaian kembali.

\section{Kesimpulan, Keterbatasan dan Saran Kesimpulan}

Berdasarkan hasil penelitian dan analisis data maka dapat ditarik beberapa simpulan yaitu Assessment Ratio (AR) pada setiap kecamatan yang berada di Kota Banda Aceh, yang terdiri dari 9 kecamatan semuanya berada di bawah standar yang direkomendasikan oleh Dirjen Pajak atau underassessment. Dengan demikian perlu dilakukannya penilaian ulang untuk dapat memaksimalkan penerimaan melalui PBB-P2 karena AR yang dihasilkan sangat rendah apabila di bandingkan dengan anjuran pemerintah melalui Dirjen Pajak. Selanjutnya penetapan NJOP di Kota Banda Aceh untuk mean, median, weighted mean, $\mathrm{COV}$ belum sesuai dengan standar yang direkomendasikan oleh IAAO (2013) atau telah terjadi under-assessment. Akan tetapi mean/median, mean/weighted mean, serta COD telah sesuai dengan standar yang ditetapkan. 
Mean/median dan mean/weighted mean sesuai dengan standar dapat dipengaruhi oleh data yang digunakan menjadi sampel cenderung sama dimana nilai di atas dan di bawah median hampir sama. Ketidakseragaman antara hasil COD dan COV maka diperlukan penilaian kembali guna nilai tanah dapat terdata secara keseluruhan sehingga dapat menambah penerimaan daerah.

\section{Keterbatasan Penelitian}

Penelitian ini masih terdapat beberapa keterbatasan antara lain yaitu penelitian ini hanya menggunakan data sekunder yang bersumber dari BPKK Kota Banda Aceh. Seharusnya dapat ditambah dengan data primer seperti wawancara dengan masyarakat untuk mengetahui nilai pasar secara real. Selanjutnya data yang dijadikan sampel diberikan langsung oleh pegawai BPKK. Hal ini dikarenakan data penjualan objek pajak telah tersistem dengan aplikasi, sehingga hanya pegawai yang dapat mengaksesnya.

\section{Saran}

Berkaitan dengan hasil penelitian yang diperoleh serta adanya keterbatasan dalam melaksanakan penelitian ini, adapun saran yang dapat diberikan yaitu bagi Pemkot Banda Aceh seharusnya pembaharuan penetapan NJOP harus dilakukan dengan lebih baik, agar NJOP mendekati harga pasar setidaknya AR yang dihasilkan tidak terlalu rendah dari anjuran baik dari Dirjen pajak maupun standar yang dikeluarkan oleh IAAO. Hal ini bertujuan supaya Pemkot Banda Aceh dapat memaksimalkan potensi PAD dan masyarakat masih mempunyai minat untuk membayar pajak. Oleh karena itu, sebaiknya Pemkot Banda Aceh melakukan tinjauan ulang terhadap pembaharuan penetapan NJOP atau melakukan penilaian ulang. Nilai dari NJOP merupakan penentu dalam penerimaan $\mathrm{PBB}-\mathrm{P} 2$, sehingga dengan penilaian ulang diharapkan dapat meningkatkan penerimaan PAD melalui PBB-P2. Bagi peneliti selanjutnya diharapkan dapat menambah objek pajak bangunan. Selanjutnya diperlukan analisis lebih lanjut mengenai kontribusi PBB-P2 terhadap PAD dan analisis lebih lanjut mengenai kegunaan hasil penerimaan daerah yang bersumber dari PBB-P2, sehigga wajib pajak dapat mengetahui apakah alokasi penerimaan dari
PBB-P2 sudah tepat sasaran dan berdampak pada pertumbuhan ekonomi.

\section{Daftar Pustaka}

Aceh.tribunnews.com. 2013. Harga Tanah

Melambung. 28 April.

http://aceh.tribunnews.com/2013/04/28/harga-tanahmelambung. diakses pada tanggal 9 Februari 2019

Aprianing, Y. D., Wilopo, \& Mayowan, Y. (2016). Potensi Pajak Bumi Dan Bangunan Sektor Perdesaan Dan Perkotaan (PBB-P2) (Studi Kasus Di Kabupaten Malang Ditinjau Dari Perbedaan Harga Pasar Wajar Dengan Nilai Jual Objek Pajak (NJOP) Bumi Yang Berlaku). Jurnal Perpajakan (Jejak), 8(1).

Auliani, S. N., Kamio, \& Supadi. (2012). Analisis Penetapan NJOP Terhadap Harga Pasar Dengan Metode Assessment Sales Ratio Dalam Kaitannya Dengan Potensi Pajak Bumi ( Studi Kasus Tanah Di Kecamatan Serpong Utara , Kota Tangerang Selatan ). Jurnal Eko-Regional, 7(2), 91-98.

Bintang, A. P., Rotinsulu, T. Ri O., \& Engka, D. S. M. (2017). Analisis Faktor-Faktor Yang Mempengaruhi Nilai Tanah Di Kota Manado. Emba, 1-18.

Cohen, C., Manion, L., \& Marrisok, K. (2007). Research Methods in Education, Sixth Edition. Oxon: Routledge

Direktorat Jederal Pajak Kementerian Keuangan (14 April 2012). Belajar Pajak

http://www.pajak.go.id/content/belajar-pajak. diakses pada tanggal 13 Januari 2019

Elriza, P. (2014). Tingkat Akurasi Penetapan NJOP Bumi Terhadap Nilai Pasar Dengan Metode Assessment Sales Ratio Di Kecamatan Sario Kota Manado Tahun 2012. Jurnal Emba, 1(1), 1-5. Https://Doi.Org/10.1007/S13398-0140173-7.2

F., F., Basong, A., \& Tagala, H. H. (2003). Identifikasi Faktor Yang Mempengaruhi Nilai Jual Lahan Dan Bangunan Pada Perumahan Tipe Sederhana. Smartek, 8 (4), 251-269.

International Association of Assessing Officers (2017), Standard on Mass Appraisal of Real Property, Missouri: International Association of Assessing Officers. 
https://www.iaao.org/media/standards/StandardOnMas sAppraisal.pdf

International Association of Assessing Officers (2013), Standard on Ratio Studies, Missouri: International Association of Assessing Officers

https://www.iaao.org/media/standards/Standard_on_R atio_Studies.pdf

Kumoro, M. P., \& Ariesanti, A. (2017). Potensi Pajak Bumi Dan Bangungan Sektor Perdesaan Dan Perkotaan Kota Yogyakarta Dan Kontribusinya Terhadap Kemandirian Daerah. Riset Akuntansi Dan Keuangan Indonesia, 2(1).

Lubis, I., Djuanda G., \& Lubis, A. (2010). Review Pajak Orang Pribadi dan Orang Asing. Jakarta: Salemba Empat

Marpaung, G. N. (2011). Analisis Faktor-Faktor Yang Mempengaruhi Konsumen Terhadap Permintaan Perumahan. Jejak, 4 (2)(September), 125-134.

Monding, R. O. H., \& Pusung, R. J. (2016). Analisis Tingkat Akurasi Penetapan Nilai Jual Objek Pajak (NJOP) Bumi Dan Bangunan Di Kecamatan Paal Dua Kota Manado. Emba, 4(4), 993-1000.

Mursito, B., \& Samrotun, Y. C. (2014). Penilaian Nilai Jual Objek Pajak (NJOP) Yang Berkeadilan Dengan Menggunakan Metode Sales Assessment Ratio. Economic And Business Research Festival, 8(33), 44.

Organisasi.org. Daftar Nama Kecamatan Kelurahan/Desa \& Kodepos Di Kota Banda Aceh Nanggroe Aceh Darussalam.

http://www.organisasi.org/1970/01/daftar-namakecamatan-kelurahan-desa-kodepos-di-kotabanda-aceh-nanggroe-acehdarussalam.html\#.XEZs5fkzbIU. Diakses pada tanggal 22 Januari 2019

Patara, W., \& Tinangon, J. J. (2016). Analisis Kontribusi, Efektivitas Dan Perhitungan PBBP2 Berdasarkan NJOP Pada Dinas Pengelola Keuangan Pendapatan Dan Aset Kabupaten. Minahasa Selatan, 4(1), 763-771.

Pramana, A. Y. E. (2017). Analisis Faktor Yang Berpengaruh Terhadap Nilai Lahan Di Kawasan Perkotaan Yogyakarta Studi Kasus Kecamatan Ngaglik, Kabupaten Sleman, Daerah Istimewa. Prosiding Seminar Nasional Xii "Rekayasa Teknologi Industri Dan Informasi 2017 Sekolah Tinggi Teknologi Nasional Yogyakarta.
Rusjdi, M. (2008). PBВ, ВРНTB, \& Bea Materai. Edisi kedua. Jakarta: PT Indeks

Suryawati, R. F., Harwida, G. A., \& Suryadi. (2010). Analisa Penetapan NJOP (Nilai Jual Objek Pajak) Pajak Bumi Terhadap Nilai Pasar Dengan Menggunakan Metode Assessment Sales Ratio, 3(1). Https://Doi.Org/10.1016/J.Chb.2018.06.004

Sutawijaya, A. (2004). Ekonomi Pembangunan Analisis Faktor-Faktor Yang Mempengaruhi Nilai Tanah Sebagai Dasar Penilaian Nilai Jual Obyek Pajak (NJOP) Pbb Di Kota Semarang. Ekonomi Pembangunan, 65-78.

Tribunnews.com. 2014. Harga Tanah di Jalan Daud Bereueh Rp 2 Jutaan Per Meter Termahal di Aceh. 4 September.

http://m.tribunnews.com/regional/2014/09/04/hargatanah-di-jalan-daud-bereueh-rp-2-jutaan-permeter-termahal-di-aceh. diakses pada tanggal 13 Januari 20191

Wakas, M., Karamoy, H., \& Runtu, T. (2015). Analisis Tingkat Akurasi Penetapan NJOP Bumi Di Kecamatan Mapanget Kota Manado. Emba, 3(2), 85-93.

Republik Indonesia. Undang-Undang Republik Indonsia Nomor 12 Tahun 1985 tentang Pajak Bumi dan Bangunan.

http://www.bphn.go.id/data/documents/85uu012.pdf. diakses pada tanggal 14 Januari 2019

. Undang-Undang Republik Indonesia Nomor 28 Tahun 2007 tentang Perubahan Ketiga atas Undang-Undang Nomor 6 Tahun 1983 Tentang Ketentuan Umum dan Tata Cara Perpajakan.

http://www.dpr.go.id/dokjdih/document/uu/UU_2007_ 28.pdf. diakses pada tanggal 13 Januari 2019

Undang-Undang Republik Indonesia Nomor 28 Tahun 2009 tentang Pajak Daerah dan Retribusi Daerah.

http://www.djpk.depkeu.go.id/attach/post-no-28-

tahun-2009-tentang pajak-daerah-dan-retribusidaerah/UU-427-973

UU_28_Tahun_2009_Ttg_PDRD.pdf. diakses pada tanggal 13 Januari 2019

Kementerian Republik Indonesia. Direktorat Jenderal Pajak.Surat Edaran Direktur Jederal Pajak Nomor SE-01/PJ.6/2003 tentang Kebijakan Pengamanan Penerimaan PBB dan BPHTB. https://peraturanpajak.com/2018/02/12/surat-edaran- 
direktur-jenderal-pajak-nomor-se-01-pj-6-2003/. diakses pada tanggal 13 Januari 2019

.Surat Edaran Direktur Jederal Pajak Nomor SE09/PJ.6/2003 tentang Penerapan NJOP Sama Dengan Nilai Pasar.

https://peraturanpajak.com/2018/02/06/surat-edarandirektur-jenderal-pajak-nomor-se-09-pj-6-2003/. diakses pada tanggal 12 Januari 2019

Pemerintah Kota Banda Aceh. Qanun Kota Banda Aceh Nomor 12 Tahun 2011 Tentang Pajak Bumi dan Bangunan Perdesaan dan Perkotaan. http://www.jdih.setjen.kemendagri.go.id/files/KOTA BANDA\% 2520ACEH 15 2011.pdf\&ved=2ah UKEwig veGybPgAHUHeisKHRurCtAQFjAC egQIARAB\%usg=AOvVaw0FsGlcLzaz6lw6lfE JDMXf\&cshid $=1549884391415$. Diakses pada tanggal 8 Februari 2019 